13 Patton WF, Lynch JP. Lymphomatoid granulomatosis. Clinicopathologic study of four cases and literature review. Medicine 1982;61:1-12.

14 Lopez Gaston JI, Oliveros A, Used MM, et al. Estudio anatomoclinico de un caso de Granulomatosis linfomatoide. Ann Med Intern (Madrid) 1986;3:342-5.

15 Pasquier B, Pasquier D, Guenlle JM, et al. Granulomatose lymphomatoide et systeme nerveux, aspects anatomocliniques et problemes nosologiques. Rev Neurol (Paris) 1980;136:205-20.

16 Verity A, Wolfson WL. Cerebral lymphomatoid granulomatosis. Report of two cases with disseminated necrotizing leukoencephalopathy in one. Acta Neuropathol (Berlin) 1976;36:117-24.

17 Vermess M, Bernstein RM, Bydder GM, et al. Nuclear Magnetic Resonance (NMR) imaging of the brain in systemic lupus erythematosus. J Comput Assist Tomogr 1983;7:461-7.

Accepted 7 March 1988

\section{Neuroleptic malignant syndrome in a patient with Wilson's disease}

Sir: The neuroleptic malignant syndrome (NMS) is a rare but potentially lethal complication of treatment with neuroleptic drugs. It is manifested by Parkinsonian symptoms accompanied by fever and signs of autonomic instability. Most of the reports of NMS concern patients with schizophrenia or major affective disorders. ${ }^{12}$ We here describe a case of NMS in a patient suffering from Wilson's disease who was taking neuroleptics. To our knowledge this is the first such report.

The patient is an 18 year old man who was well until August 1984. Pregnancy and birth were normal and no serious illness during childhood was reported. He has an older sister who is healthy. His parents are also healthy and not consanguineous. In September 1984 he showed evidence of mental disturbance. He became agitated and began to experience delusions (mainly of a persecutory and homosexual content) and visual and auditory hallucinations. He slept poorly and had anorexia and weight loss. In April 1985, $4 \mathrm{mg}$ haloperidol, $90 \mathrm{mg}$ thioridazine and $6 \mathrm{mg}$ biperiden daily were started. His mental state improved but he developed marked Parkinsonian features and medication was discontinued 10 days later. Until August 1985, the patient was drug free but the Parkinsonian signs, mainly a left hand rest tremor, persisted. During this drug free period he again became agitated, deluded and hallucinated. He was then given
$300 \mathrm{mg}$ chlorpromazine, $25 \mathrm{mg}$ loxapine, 4 $\mathrm{mg}$ trifluoperazine and $150 \mathrm{mg}$ orphenadrine daily. A few days later his mental state was improved, but the Parkinsonian signs worsened. These drugs were therefore stopped. In November 1985, the patient was receiving only $20 \mathrm{mg}$ diazepam and $150 \mathrm{mg}$ orphenadrine daily. Just before admission to Eginition Hospital (8 January 1985) there was an exacerbation of his psychiatric symptoms. $30 \mathrm{mg}$ haloperidol, $300 \mathrm{mg}$ chlorpromazine and $15 \mathrm{mg}$ trihexyphenidyl daily were restarted. On admission he was sweating profusely, dysarthric with marked sialorrhoea, rigidity, choreiform movements, opisthotonic posturing and fever $\left(39 \cdot 3^{\circ} \mathrm{C}\right)$. He required help to be fed, while his conscious level fluctuated. The respiratory rate was $29 / \mathrm{min}$ and the pulse $130 / \mathrm{min}$. Blood pressure was $145 / 80 \mathrm{~mm} \mathrm{Hg}$. From time to time he developed oculogyric crises accompanied by retrocollis and elevation in blood pressure (to $180 / 120 \mathrm{~mm} \mathrm{Hg}$ ) of about 10 min duration. The following day all neuroleptic drugs were discontinued. On 15 January he received only $15 \mathrm{mg}$ diazepam and $80 \mathrm{mg}$ propranolol daily. On neurological examination he was cooperative. $\mathrm{He}$ showed fixity of facial expression. His fundi and pupils were normal. Tongue movements were very limited. Both arms were very rigid. Power was normal but discrete finger movements were very poorly performed. The tendon reflexes were sluggish, abdominal reflexes symmetrical, and both plantar responses flexor. There was no detectable sensory deficit and general examination was normal. A detailed investigation of the blood, liver, and thyroid function was performed. Other investigation included: antinuclear, anti-DNA and antiviral antibodies, C-reactive protein, $\alpha$ antistreptolysin-O, ECG, EEG, muscle biopsy, motor and sensory conduction velocity. Wright, Widal, Weil-Felix, Paul-Bunnel, VDRL, ELISA test were also performed and urine, blood and CSF cultured. All these tests and laboratory data were normal except an elevation of serum CK (340 U/l, normal up to 76) and aldolase (9.8 U/1, normal up to 7.6). Computed tomography of the brain showed moderate ventricular enlargement without changes in the region of the basal ganglia. The serum caeruloplasmin level was severely reduced at $0.06 \mathrm{~g} / 1$ (normal $0.2-0.4$ ) and the serum copper level was also reduced at $5 \cdot 7$ $\mu \mathrm{mol} / 1$ (normal 11.0-22.0). Urinary copper excretion over $24 \mathrm{~h}$ was abnormal at 4.4 and $5 \cdot 1 \mu \mathrm{mol} / 1$ (normal 0-1.0). Liver biopsy showed evidence of cirrhosis with deposition of copper and copper associated protein. Kayser-Fleisher rings were readily detectable with a slit lamp. The diagnosis of Wilson's disease was therefore clearly confirmed during the next 20 days his condition deteriorated. Tone was greatly increased in all muscle groups and his temperature rose to $39 \cdot 5^{\circ} \mathrm{C}$. Finally he became mute, withdrawn and unresponsive. Because of his elevated serum CK, high fever, extrapyramidal signs and autonomic dysfunction the diagnosis of NMS was made. Bromocriptine up to $40 \mathrm{mg} /$ day, dantrolene 200 $\mathrm{mg} /$ day and amantadine $200 \mathrm{mg} /$ day were given. Shortly afterwards the patient's condition, including conscious level, muscular rigidity and fever improved considerably. On 5 March, the temperature was normal and remained so afterwards. He was able to feed himself and he could also stand up and walk with support. In contrast his mental condition deteriorated. On 12 March ECT was started and gradually the drug doses were reduced. By 5 April, after 12 ECT treatments he was receiving. no drugs except for $80 \mathrm{mg} /$ day propranolol. He was able to speak and communicate. The elevated serum enzymes (CK and aldolase) fell to normal. His psychotic condition was improved with the exception of his impulsive behaviour Because of the primary diagnosis (Wilson's disease) at this stage (June 1986) treatmenn with penicillamine $500 \mathrm{mg} /$ day was initiated $\overline{ }$ One week later this treatment was discon tinued because of leucopenia and thrombocytopenia. In September 1986 treatment with trientine dihydrochloride $1200 \mathrm{mg} /$ dase was started. The results of 24 hour coppes excretion estimation indicated a reduction to the normal limits. One year later (February 1987) the patient is psychiatrically and neurologically well apart from slight rigidity (mainly of the left hand) and dysarthria. During all this last period (6 months) he received $1200 \mathrm{mg}$ trientine dihydrochloride, $30 \mathrm{mg}$ diazepam and $12 \mathrm{mg}$ benzexol daily and there was no need to give any neuroleptic drug.

The patient fulfilled all the primary criteria for NMS given by Levenson ${ }^{3}$ (fever, rigidity, increased $\mathrm{CK}$ ) and five of his six secondary criteria (only leucocytosis exempted). In addition the patient met all the three criteria for the definite diagnosis of NMS given by Pope et $a^{4}$ (hyperthermia, severe extrapyramidal effects, autonomic dysfunction). To our knowledge no case of NMS in a patient with Wilson's disease has hitherto been reported though NMS cases in patients with organic brain syndromes, mainly with basal ganglia pathology, such as Huntington's chorea or Parkinson's disease, have been described. ${ }^{56}$ Caroff $^{7}$ has suggested that organic brain diseases might be 
a factor predisposing to the syndrome. Residual neurological sequelae have been described in some patients with NMS, mostly signs of Parkinsonism or decrease of general intellectual faculties. ${ }^{8-10}$ Our patient who had a long and severe course in relation to the syndrome was left with a hypertonia (mainly of the left hand) and dysarthria, though we cannot tell whether they are due to his Wilson's disease or to the NMS.

The authors thank Prof P K Thomas, Royal Free Hospital, University of London, for his valuable advice and help in the treatment of the patient. M Markianos PhD and G Vaslamatzis MD were also very helpful commenting on the manuscript.

VASSILIS KONTAXAKIS COSTAS STEFANIS MARIOS MARKIDIS VASSILIKI TSERPE Department of Psychiatry, Athens University Medical School, Eginition Hospital 74, Vas Sophias Avenue, 11528 Athens, Greece

\section{References}

1 Shalev A, Munitz H. The Neuroleptic malignant syndrome: agent and host interaction. Acta Psychiatr Scand 1986;73:337-47.

2 Addonizio G, Susman V, Roth S. Neuroleptic malignant syndrome: review and analysis of 115 cases. Biol Psychiatry 1987;22:1004-20.

3 Levenson JL. Neuroleptic malignant syndrome. Am J Psychiatry 1985;142:1137-45.

4 Pope HG, Keck PE, McElroy SL. Frequency and presentation of Neuroleptic malignant syndrome in a large Psychiatric Hospital. Am J Psychiatry 1986;143:1227-33.

5 Burke RE, Fahn S, Mayeux R, Weinberg M, Louis K, Willner JH. Neuroleptic malignant syndrome caused by dopamine-depleting drugs in a patient with Huntington disease. Neurology 1981;31:1022-6.

6 Henderson VF, Wooten GF. Neuroleptic malignant syndrome: a pathogenetic role for dopamine receptor blockade? Neurology 1981;31:132-7.

7 Caroff SN. The Neuroleptic malignant syndrome. J Clin Psychiatry 1980;41:75-83.

8 Eiser AR, Neff MS, Slifkin RF. Acute myoglobinuric renal failure: a consequence of the Neuroleptic malignant syndrome. Arch Intern Med 1982;142:601-3.

9 Cohen WJ, Cohen NH. Lithium carbonate haloperidol, and irreversible brain damage. JAMA 1974;230:1283-7.

10 Meuller PS, Vester JW, Fremglich J. Neuroleptic malignant syndrome: successful treatment with bromocriptine. JAMA 1982;249. 386-8.
Brain death and pinpoint pupils

Sir: Non-reactive pupils are one of the cardinal signs in brain death. Contrary to what was required at one stage ${ }^{1}$ it is no longer considered necessary for the pupils to be dilated. In fact they are most often found to be in the mid position. ${ }^{23}$ Pinpoint pupils are not a feature of brain death and may be the result of a bilateral pontine lesion affecting the sympathetic fibres. That pinpoint pupils may be seen in verified brain death is evident from the following case.

The patient was a 69 year old woman with coronary heart disease for 12 years, and one mild ischaemic stroke two months before carotid endarterectomy. The endarterectomy was performed successfully but twenty hours after operation the sutures of the carotid artery ruptured resulting in a profuse bleeding. The huge haematoma in the neck prevented intubation, and an emergency tracheostomy was performed. During about ten minutes the respiration was severely impaired and the situation was further complicated by cardiac arrest. After ten minutes' resuscitation the heart began to beat but the intra-arterially measured blood pressure readings stayed for 80 minutes at the level of $30-50 \mathrm{~mm} \mathrm{Hg}$ systolic. The patient did not regain consciousness, and six hours later she was deeply comatous with no pupillary reactions, no response to the oculo-cephalic test, and no grimacing during firm compression of the supraorbital nerves. The patient was ventilated for ten minutes with $100 \%$ oxygen and then disconnected from the respirator for 10 minutes. During the disconnection $100 \%$ oxygen was insufflated into the trachea at a rate of 6 $1 / \mathrm{min}$. At the time of the disconnection the $\mathrm{PaCO}_{2}$ level was $4.5 \mathrm{kPa}$ which, according to a recent study ${ }^{4}$ results in final $\mathrm{PaCO}_{2}$ levels giving a maximal stimulation of the respiratory centre. No spontaneous breathing movements occurred during the test. Because the non-reactive pupils were of pin-point size and thus not in accordance with the criteria of brain death, the patient was again connected with the respirator. Twenty-four hours later the examination gave the same result, the pupils were still of pinpoint size. The scrutiny of the case history revealed glaucoma treated with pilocarpine eye drops given twice daily in both eyes before and after surgery. The patient was disconnected from the respirator, and two days later a medicolegal necropsy showed a typical respirator brain.

Our case emphasises the importance of a thorough scrutiny of the medication used in case of suspect brain death. In his excellent articles on brain stem death Pallis mentions as pitfalls in the diagnosis anticholinergic drugs, neuromuscular blockers, and pre existing eye disease. ${ }^{3}$ In 1971 , Wexler $\stackrel{5}{=}$ reported of two patients in irreversible como with non-mydriatic pupils who had been using miotics for glaucoma. We would like to add pilocarpine to the list of pitfalls in the diagnosis of brain death. It acts as a cholinomimetic directly on cholinergic receptors, an effect which is not abolished by denervation Because glaucoma is common especially among older people, and is often treatec with pilocarpine, this possible cause of miotic pupils in suspect brain death must be kept in mind.

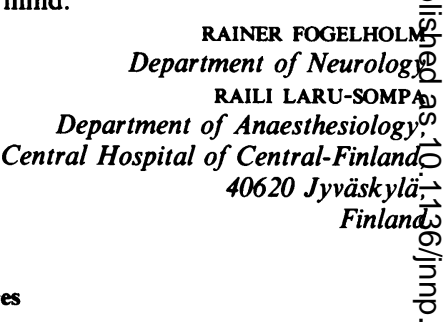

References

1 Report of the Ad Hoc Committee of the Harvard Medical School to Examine The Definition of Brain Death. $J A$ 1968;205:337-40.

2 Prognosis in coma and the diagnosis of bre death. In: Plum F, Posner JB. Diagnos Stupor and Coma. Philadelphia: FA De Co, 1978:224-39.

3 Pallis C. ABC of brain stem death. Pitfalls safeguards. Br Med J 1982;285:1720-2.

4 van Donselaar CA, Meerwaldt JD, van Gi Apnoea testing to confirm brain deatpipifo clinical practice. $J$ Neurol Neurosurg Psychiatry 1986;49:1071-3.

5 Wexler J. Pupils size and irreversible coma. Engl J Med 1971;285:526.

Accepted 7 March 1988

Acute dystonic reaction with asterixis and myoclonus following metoclopramide therap

Sir: Extrapyramidal side effects are weIt recognised following medication wit复 metoclopramide, a selective D2 dopamine antagonist. ${ }^{12}$ Some $95 \%$ of these effects are of the acute dystonic-dyskinetic type. The occur mostly in younger females, within 79 hours of taking the drug, and disappeat without specific treatment. Oculogyrie crises, torticollis, opisthotonos, and orofacial dyskinesias are often present. However, the occurrence of asterixis an myoclonus together with acute dystonios reactions has not been reported. WR observed such a patient. 